\title{
Individual behavior of first-price auctions: The importance of information feedback in computerized experimental markets
}

\author{
Tibor Neugebauer ${ }^{\mathrm{a}, *}$, Reinhard Selten ${ }^{\mathrm{b}}$ \\ ${ }^{a}$ Universität Hannover, Lehrstuhl FMT, Königsworther Platz 1, 30167 Hannover, Germany \\ ${ }^{\mathrm{b}}$ Friedrich-Wilhelm-Universität Bonn, Laboratorium für Experimentelle Wirtschaftsforschung, \\ Adenauerallee 24-42, 53113 Bonn, Germany
}

Received 6 October 2004

\begin{abstract}
This article reports the results of an individual choice experiment designed to test the Nash equilibrium predictions of the first-price sealed-bid auction. A subject faced in 100 auctions always the same resale value and competed with computer-simulated bids. The design used between-subjects variation and involved information feedback as the treatment variable. Earlier experimental work on first price auctions has frequently reported an overbidding relative to the risk neutral Nash equilibrium. Our data provide evidence that overbidding can be fostered by the standard information feedback in auction experiments, which, after each auction, reveals the winning bid only. By means of learning direction theory we explain the individual bidding dynamics in our experiment. Finally we apply impulse balance theory and make long run predictions of individual bidding behavior.
\end{abstract}

(c) 2005 Elsevier Inc. All rights reserved.

JEL classification: $\mathrm{C} 12 ; \mathrm{C} 13 ; \mathrm{C} 72 ; \mathrm{C} 92 ; \mathrm{D} 44$

Keywords: Experimental economics; First-price sealed-bid auctions; Independent private value model; Computerized competitors; Bidding theory; Risk aversion

\footnotetext{
This paper is part of the EU-TMR Research Network ENDEAR (FMRX-CT98-0238).

* Corresponding author. Fax: +49 5117625240.

E-mail address: t.neugebauer@mbox.vwl.uni-hannover.de (T. Neugebauer).
} 


\section{Introduction}

This article reports the results of an individual choice experiment designed to test the Nash equilibrium predictions of the first-price sealed-bid auction (hereafter FPA). The design of the experiment involves a repeated setting with three different feedback information treatments. Our experimental data reveal that subjects adjust their bids in response to the received feedback information, and these adjustments are more frequent when information feedback is clear in terms of foregone payoff than when it is ambiguous. We observe that subjects submit relatively higher bids when their feedback information is clear after losing and ambiguous after winning than when they face either clear feedback information or ambiguous feedback information in both experience conditions. In particular, we observe overbidding relative to the risk neutral Nash equilibrium of FPA in the former treatment and underbidding in the latter treatments, respectively. Since the commonly applied theories of Nash equilibrium bidding concern the one-shot game they do not assume adjustment dynamics and fail to predict the treatment effect we observe. Therefore, we must reject them as descriptive bidding theories for the repeated game on the basis of our experimental data. We propose impulse balance theory (Selten, 2004; Selten et al., 2005; Ockenfels and Selten, 2005) as an alternative, boundedly rational equilibrium concept.

Impulse balance theory accounts for the feedback information conditions in the repeated game, and thus yields different point predictions for different feedback conditions. In principle, impulse balance theory weighs the foregone payoff upon losing against the foregone payoff upon winning. The impulse balance point in our experiment is the bid at which the probability weighted foregone payoffs from losing and winning equalize. The theory is based on learning direction theory (Selten and Stoecker, 1986; Selten and Buchta, 1994) which is a qualitative learning theory. Learning direction theory has been supported by experimental data on auctions (Selten and Buchta, 1994; Kagel and Levin, 1999; Selten et al., 2005; Ockenfels and Selten, 2005) and on many other repeated experimental settings (for a review, see Selten, 2004). In our experiments, the bidding dynamics of 92 percent of all subjects agree with the behavioral patterns proposed by learning direction theory.

In contrast to impulse balance theory, the standard approach to the FPA assumes that all bidders maximize utility. Vickrey (1961) showed the existence of a symmetric risk neutral Nash equilibrium (hereafter RNNE). The RNNE maximizes expected payoff if and only if all bidders have identical subjective probabilities and identical strategies. ${ }^{1}$ The RNNE was first challenged by Coppinger et al. (1980) who conducted an experiment, in which subjects interacted repeatedly with each other in experimental auction markets. Their main result with respect to the FPA was that winning bids exceeded significantly the RNNE prediction. ${ }^{2}$ Overbidding relative to the RNNE prediction has been reported thereafter from several FPA experiments (for a review, see Kagel, 1995). In order to provide an explanation for the observed overbidding, Cox et al. (1982a, 1982b, 1983a, 1983b, 1984, 1985a, 1985b, 1987, 1988) developed the constant relative risk aversion model (hereafter CRRAM) that generalizes Vickrey's model as it allows for heterogeneity of bidders. In the CRRAM, bidders maximize expected utility subject to their subjective probabilities about the competitors' bids. The CRRAM did not only find supporters but rather divided

\footnotetext{
1 Unilateral application of the RNNE must not be profitable as revealed by a tournament of bidding strategies for the sequential FPA (Neugebauer, 2004). In the tournament, the RNNE strategy underperforms a market that is composed of strategies submitted by experimental subjects.

2 Subjects participated three times in ten auctions. In each auction they received a resale value drawn from a discrete uniform distribution and at the end of every auction the winning bid was revealed.
} 
the experimental community. The most famous argument goes back to Harrison (1989) who criticized the methodology of Cox et al. According to Harrison's opinion, the foregone expected payoffs of subjects were more important than the deviation of the bids from the equilibrium, and in the data there were only very small incentives in terms of foregone expected payoff. This argument provoked a polemic discussion among experimental economists (Friedman, 1992; Kagel and Roth, 1992; Cox et al., 1992; Merlo and Schotter, 1992; Harrison, 1992). ${ }^{3}$ Although there was some agreement that investigating individual behavior with respect to the 'payoff space' was not more important than with respect to the 'message space' (Cox et al., 1992; Friedman, 1992; Kagel and Roth, 1992; Harrison, 1992), doubts remained whether the CRRAM actually can offer a reliable explanation for the observed overbidding. ${ }^{4}$

The experimental results presented in this article suggest that the overbidding in FPA experiments may be fostered by the commonly applied feedback information conditions that reveal the winning bid only. This would be in line with other experimental results on FPA in which different feedback conditions are applied (Isaac and Walker, 1985; Dufwenberg and Gneezy, 2002; Ockenfels and Selten, 2005; Neugebauer and Perote, 2005). In fact, our data do not warrant such a general statement, as our experiment does not describe the auction market in all its facets. We transform the original FPA-problem from a game of $N$ human opponents and Nature to a game of one human bidder against Nature. Subjects face a repeated setting with a constant resale value and invariable objective probabilities about the bidding behavior of the others. As the $N-1$ computer-simulated competitors bid 'as if' risk neutral the Nash equilibrium predictions in our environment are straight-forward. The CRRAM requests a degenerate bid that maximizes expected utility in all repetitions, and the RNNE bid maximizes expected payoff. ${ }^{5}$ Hence, our environment makes a meaningful test of bidding theories possible, but this control may come with a loss of generality. The bidding dynamics can be different when subjects interact with each other than when they interact with Nash robots. ${ }^{6}$

The article is organized as follows. The following, second section presents the theoretical Nash equilibrium models, the RNNE and the CRRAM. Thereafter the details of the experimental design are outlined and the equilibrium predictions are spelled out. These equilibrium predictions include over- and underbidding relative to the RNNE, depending on the risk aversion parameter. In the third section we report the experimental results. We observe both over- and underbidding and estimate the individual risk preference parameters according to the CRRAM. We learn that the CRRAM cannot accommodate the data. The fourth section examines the bidding dynam-

\footnotetext{
3 Other contributions relate to this discussion (Kagel et al., 1987; Harrison, 1990; Kagel and Levin, 1993; Smith and Walker, 1993; Selten and Buchta, 1994; Chen and Plott, 1998; Van Boening et al., 1998; Goeree et al., 2002; Dorsey and Razzolini, 2003; Neugebauer, 2004; Ockenfels and Selten, 2005; Neugebauer and Pezanis-Christou, in press; Neugebauer and Perote, 2005).

4 For instance, Kagel and Roth (1992) argued that risk aversion might be one of the forces of the overbidding in experimental auctions but not necessarily the most important one. As an example in which risk aversion could not explain the data from auction experiments they referred to the observations of Kagel et al. (1987) and Kagel and Levin (1993) that bidding above the dominant bid price occurred in second price auctions and to Cox et al. (1984) observation of underbidding in four out of ten treatment conditions with multiple unit discriminative auctions.

5 This does not test all possible features of the CRRAM. In the CRRAM, the Nash equilibrium usually has two parts, one part linear and one non-linear. Our experiment concerns the linear part only.

6 While Cox et al. (1987) find no difference in bidding behavior between experimental market participants and subjects who competed with Nash automata in the FPA, Neugebauer (2004) observes an important interaction effect in the strategies which subjects submitted for a sequential FPA tournament. Neugebauer reports that strategies are functions of observed bids when subjects previously had experienced an interactive market experiment, but when subjects had experienced a competition with Nash automata, strategies depend on values only.
} 
ics and reviews learning direction theory and impulse balance theory. Finally, the fifth section summarizes and concludes.

\section{Equilibrium models and experimental design}

\subsection{Risk neutral Nash equilibrium-RNNE}

In the FPA each of the $N>1$ bidders who compete in a market submits a sealed bid. The bidder who submits the high bid wins the auction and pays a price equal to his bid. Consider the independent private value model, in which each bidder has private information only about his own resale value and knows the distribution from which all resale values are independently and identically drawn. Vickrey (1961) showed the existence of a symmetric, unique Nash equilibrium in the FPA for the case of risk neutral bidders. Let $b_{i}$ denote bidder $i$ 's bid, $i=1, \ldots, N$, and let $v_{i}$ be his resale value, which is drawn from the continuous uniform distribution over the interval $[0,1]$; the RNNE bidding strategy can be written as

$$
\text { RNNE: } \quad b_{i}^{*}\left(v_{i}\right)=\frac{N-1}{N} \cdot v_{i} .
$$

The RNNE strategy can be interpreted as the bid that equals a bidder's expectation about the greatest resale value of his competitors given this value is smaller than his own. There is no dominant strategy in the FPA. The RNNE is only a best response, if all bidders adhere to it. The existence of the Nash equilibrium crucially hinges on the bidders' identical beliefs and identical strategies.

\subsection{Constant relative risk aversion model_CRRAM}

An overbidding relative to the RNNE has been observed in many FPA experiments. In order to theoretically account for this regularity, Cox et al. (1982a, 1982b, 1983a, 1983b, 1984, 1985a, 1985b, 1987, 1988) developed the constant relative risk aversion bidding model (hereafter CRRAM) which generalizes Vickrey's model, as it allows for heterogeneity of bidders. In the standard presentation of the CRRAM each bidder $i$ is defined by an Arrow-Pratt constant relative risk aversion of $1-r_{i}$, where $r_{i}$ (the risk preference parameter) has any probability distribution on the unit-interval. Let the resale values $v_{i}, i=1, \ldots, N$, be independently drawn from a continuous uniform distribution over the interval $[0,1]$. If no bid exceeds the maximum bid of a risk neutral bidder, $\forall i b_{i} \leqslant(N-1) / N$, the Nash equilibrium bidding strategy in the CRRAM writes as

$$
\text { CRRAM: } \quad b_{i}^{*}\left(v_{i}, r_{i}\right)=\frac{N-1}{N-1+r_{i}} \cdot v_{i} .
$$

(In the presence of bids greater than $(N-1) / N$ there is no closed-form solution.) Just as in the risk neutral model, there is no dominant bidding strategy in the CRRAM, the Nash equilibrium depends on the bidder's belief that all other bidders bid constant fractions of their resale value. The RNNE is a special case of the CRRAM if all bidders are risk neutral, i.e., $\forall i r_{i}=1$. Riskaverse bidders $\left(r_{i}<1\right)$ bid above the RNNE.

Note that the CRRAM is more flexible than the RNNE in accommodating data as it allows for individually different risk preferences. Under the common knowledge assumption with respect to the probability distribution of risk preferences every bidder maximizes against the equilibrium of the one-shot game. From the rationality point of view it is questionable whether this concept 
should be applied to repeated games, since an application to repeated games would demand for a Bayesian updating after each observation, and this is not done.

\subsection{Experimental design}

As in Cox et al. (1987) and in Harrison (1989), the experimental design involves computerized competitors. Experimental subjects, who were mainly undergraduate economics students, participated in 100 auctions in each of which they received a resale value of 100 experimental currency units ECU, and were asked to place a bid against the bids of $N-1$ computerized competitors, where $N=\{3,4,5,6,9\} .{ }^{7}$ In every auction, the bids of the computerized competitors were randomly drawn from a uniform distribution ranging from 0 to 100. According to the FPA, subjects won an auction if they submitted the high bid. If they won the auction they received a payoff equal to the difference between the resale value (100 ECU) and their bid, otherwise they received nothing. At the end of the experiment, subjects were paid their accumulated payoff in Italian Lire at an exchange rate of $1 \mathrm{ECU}=5 \mathrm{~N}$ ITL. ${ }^{8}$ Subjects were instructed accordingly, including a detailed description of the computer software. ${ }^{9}$ Subjects performed the task at their own pace (between 30-60 minutes); when finished they were paid and left. In total, 174 subjects who had no prior experience at auction experiments participated in one of the 15 experimental sessions performed in May 2001 at the ESSE laboratory of the University of Bari, in Italy.

The design used between-subjects variation and involved information feedback as the treatment variable. Three treatments (below referred to as $T 0, T 1$ and $T 2$ ) were considered which differed with respect to the on-screen information displayed after every auction. Each subject was exposed to one information feedback treatment and to one market size $N$. In treatment $T 0$, subjects received no quantitative information about the highest bid of the computerized competitors; they were just informed whether the highest bid of the competitors was above or below their own bid. In $T 1$, the highest bid of the competitors was revealed only if it was higher than the own bid, i.e., the winning bid was revealed always; this feedback condition corresponds to the FPA experiments of Cox et al. In $T 2$, the highest bid of the computerized competitors was revealed in every auction.

\subsection{Equilibrium predictions in the experiment}

The bidding game of our experiment involves one bidder who faces the value $v=1$ (in the experiment represented by $100 \mathrm{ECU}$ ) which equals the upper bound of the uniform distribution from which the $N-1$ competitors' bids are identically and independently drawn. The competitors' bids can be interpreted as RNNE bids drawn from $U[0 ; 1]$ corresponding to values drawn from the interval $U[0 ; N /(N-1)]$, since drawing RNNE bids from $U[0 ; 1]$ is equivalent to drawing values from $U[0 ; N /(N-1)]$ and applying the RNNE strategy. Thus, the subjects' value equals the maximum bid that would be submitted by a risk neutral competitor. This is important, because the CRRAM of bidding has a non-linear segment above this point. In the

\footnotetext{
7 These market sizes correspond to the ones used in the research of Cox et al.

8 The average payoff was 16,000 ITL $\approx 8$ EUR (US\$8). Subjects were highly motivated by this amount since they had no alternative job offers and less than $\$ 100$ to spend per month.

9 Please find the instructions in Appendix A. The computer software was prepared by means of Abbink and Sadrieh's (1995) RatImage. The accumulated payoff, all historical bids and all results were displayed in a table on a subject's screen.
} 
bidding game of our experiment, risk-averse bidders $\left(r_{i}<1\right)$ and risk-preferring bidders $\left(r_{i}>1\right)$ would bid according to (2), and a risk-neutral bidders $\left(r_{i}=1\right)$ would submit the RNNE bid as described in (1). This is shown in Appendix A. In fact, the Nash equilibrium predictions do not alter between treatments $T 0-T 2$, as feedback information conditions do not affect the CRRAM.

\section{Do we observe over- or under-bidding?}

\subsection{First bids}

We begin the analysis of the experimental data considering subjects' first bids, which are especially interesting because they were submitted before subjects gathered any experience. As pointed out above, a commonly observed behavioral pattern in FPA experiments is that subjects overbid the RNNE. Cox et al. (1982a, 1982b, 1983a, 1983b, 1984, 1985a, 1985b, 1987, 1988) explained the overbidding behavior by means of risk aversion. Table 1 records the number of subjects who bid above, at or below the $\mathrm{RNNE}^{10}$ : 5 out of 174 subjects (3\%) submitted bids as predicted by the RNNE, and 39 subjects (22\%) submitted bids which exceeded the RNNE prediction in the first auction. Hence, 25 percent of the submitted bids of the first auction bid 'as if' risk averse according to the CRRAM. Underbidding occurred in all treatments with a similar intensity. The bids submitted in the first auction did not change significantly between treatments $T 0-T 2 .^{11}$

Table 1

Frequencies $^{\mathrm{a}}$ of overbidders, underbidders and RNNE-bidders in auction 1: subjects classified according to their bid submitted in the first auction

\begin{tabular}{|c|c|c|c|c|c|c|c|c|}
\hline \multirow[t]{2}{*}{ Treatment } & & \multicolumn{5}{|l|}{$N^{\mathrm{b}}$} & \multirow{2}{*}{$\begin{array}{l}\text { Row } \\
\text { total }\end{array}$} & \multirow[t]{2}{*}{$(\%)^{c}$} \\
\hline & & 3 & 4 & 5 & 6 & 9 & & \\
\hline \multirow[t]{3}{*}{$T 0$} & \#underbidder & 4 & 7 & 9 & 8 & 10 & 38 & $(70)$ \\
\hline & \#overbidder & 6 & 5 & 3 & 2 & - & 16 & (30) \\
\hline & \#RNNE-bidder & - & - & - & - & - & - & \\
\hline \multirow[t]{3}{*}{$T 1$} & \#underbidder & 10 & 11 & 6 & 6 & 12 & 45 & $(75)$ \\
\hline & \#overbidder & 2 & - & 5 & 6 & - & 13 & (22) \\
\hline & \#RNNE-bidder & - & 1 & 1 & - & - & 2 & (3) \\
\hline \multirow[t]{3}{*}{$T 2$} & \#underbidder & 10 & 9 & 9 & 10 & 9 & 47 & $(78)$ \\
\hline & \#overbidder & 1 & 3 & 3 & 1 & 2 & 10 & (17) \\
\hline & \#RNNE-bidder & 1 & - & - & 1 & 1 & 3 & $(5)$ \\
\hline \multirow{3}{*}{$\begin{array}{l}\text { Column } \\
\text { total }\end{array}$} & \#underbidder & 24 & 27 & 24 & 24 & 31 & 130 & $(75)$ \\
\hline & \#overbidder & 9 & 8 & 11 & 9 & 2 & 39 & $(22)$ \\
\hline & \#RNNE-bidder & 1 & 1 & 2 & 1 & 1 & 5 & (3) \\
\hline
\end{tabular}

a Number of subjects are recorded whose first bid was above (overbidder), below (underbidder) or at the RNNE (RNNE-bidder).

b Market-sizes are indicated by the number of bidders $N$; subjects competed with $N-1$ computerized bids.

c Percentages relate to the ratio of the column total to the respective treatment total.

\footnotetext{
10 Individual statistics, including first bids, are listed in Table A.1 in Appendix A.

11 Given $N$, the null-hypothesis of equal bids in the three treatments cannot be rejected by a Kruskal-Wallis test at a significance level of $\alpha=0.05$. The $p$-values for the samples with $N=\{3 ; 4 ; 5 ; 6 ; 9\}$ are respectively $p=$ $\{0.07 ; 0.19 ; 0.34 ; 0.06 ; 0.84\}$.
} 
Our experimental data suggest that most subjects' bids cannot be explained by risk aversion according to the CRRAM (the $95 \%$ confidence band extends from 68 to $81 \%$ ). A binomial test rejects $(p=0.00)$ the null hypothesis that the submitted bid of the first auction is as likely above or at the RNNE as below the RNNE. Other factors besides full rationality seem to guide subjects' first bid choices. For instance, some of the observed bids can be explained by prominent number considerations $^{12}: 58$ percent of observed numbers are multiples of five. The likelihood of drawing randomly a number divisible by five is twenty percent. A binomial test accepts $(p=0.00)$ the alternative hypothesis that the likelihood of observing bid choices which are multiples of five is greater than 20 percent. However, an explanation of the bids submitted for the first auction lies beyond the scope of this article.

\subsection{Mean bids, bid spreads and individual risk preference parameters}

Cox et al. (1988) estimated the bid function $b(v, r)$ by ordinary least square regression. In the present study, subjects' values were fixed to 100 ECU, the upper bound of the interval, from which competitors' bids were drawn. As an estimate of the 'bid function' we use, hence, the arithmetic mean of the individual's bids. Table 2 records (in every first row) the average mean bids and (in every second row) the average risk preference parameters. ${ }^{13}$ The average mean bids in $T 1$ exceed not only the RNNE prediction for every given market-size $N$ but also the corresponding average mean bids of the other treatments. On average a risk preference parameter $r_{\text {mean }}(T 1)=0.78$ was estimated for treatment $T 1$. Following Cox et al. (1982a, 1982b) a risk preference parameter smaller than one indicates bidding above the RNNE. This overbidding pattern is in accordance with the results reported from other FPA experiments, as has been pointed out above. We observe overbidding in $T 1$, although the expected payoff would have been maximized at the RNNE bid. Comparing the results of $T 1$ to the other treatments, nevertheless, we find that overbidding is not a consistent characterization of the data. The average mean bids and the risk preference parameters estimated for $T 0, r_{\text {mean }}(T 0)=1.25$, and $T 2, r_{\text {mean }}(T 2)=1.17$, suggest underbidding rather than an overbidding pattern. Between treatments we observe significant differences in the individual average bids: for $N>4$, Kruskal-Wallis tests reject the null hypotheses of equal mean bids across treatments $T 0-T 2$ at a significance level of $\alpha=0.05$, with no significant differences for $N=3$ and $4 .^{14}$

Table 2 records (in each third row) the number of subjects whose average bids exceeded the RNNE, designating them as overbidders, while the remaining number of subjects whose average bid were below the RNNE, could be designated accordingly as underbidders. Cox et al referred to subjects who bid above the RNNE as risk averse and to those who bid below the RNNE as risk preferring.

In $T 1$, the mean bids of 75 percent of subjects exceeded the RNNE (the $95 \%$ confidence interval extends from 64 to $86 \%$ ). A one-tailed Wilcoxon signed ranks test on the individual preference parameters accepts $(p=0.00)$ the alternative hypothesis that $T 1$ is better characterized by overbidding than by underbidding. In $T 0$ and $T 2$, however, the number of underbidders exceeded the number of overbidders. For $T 0$ or $T 2$, the one-tailed Wilcoxon signed ranks test cannot reject the null hypothesis that a subject is at least as likely an underbidder as an over-

\footnotetext{
12 See Albers (2001) for a theory on prominent numbers and its applications.

13 (As in Fn. 10) Individual statistics, including risk aversion parameters, are listed in Table A.1 in Appendix A.

14 We tested the individual mean bids for given market-size between treatments. The $p$-values for the samples with $N=\{3 ; 4 ; 5 ; 6 ; 9\}$ are respectively $p=\{0.43 ; 0.90 ; 0.00 ; 0.00 ; 0.00\}$.
} 
Table 2

Average mean bids, average preference parameters of each market size and frequencies of overbidders ${ }^{\mathrm{a}}$

\begin{tabular}{|c|c|c|c|c|c|c|c|}
\hline \multirow[t]{2}{*}{ Treatment } & & \multicolumn{5}{|l|}{$N^{\mathrm{b}}$} & \multirow{2}{*}{$\begin{array}{l}\text { Row } \\
\text { total }\end{array}$} \\
\hline & & 3 & 4 & 5 & 6 & 9 & \\
\hline \multirow[t]{4}{*}{$T 0$} & Average bid ${ }^{\mathrm{a}}$ & 70.2 & 76.3 & 76.9 & 80.3 & 81.2 & \\
\hline & Average $r^{\mathrm{a}}$ & 0.89 & 1.01 & 1.26 & 1.25 & 1.89 & 1.25 \\
\hline & \#overbidders $^{\mathrm{c}}$ & 7 & 8 & 5 & 2 & 0 & 22 \\
\hline & $(\%)$ & (70) & (67) & (42) & (17) & $(0)$ & (41) \\
\hline \multirow[t]{4}{*}{$T 1$} & Average bid ${ }^{\mathrm{a}}$ & 73.7 & 77.9 & 85.8 & 88.2 & 89.7 & \\
\hline & Average $r^{\mathrm{a}}$ & 0.78 & 0.87 & 0.67 & 0.68 & 0.92 & 0.78 \\
\hline & \#overbidders ${ }^{\mathrm{b}}$ & 8 & 8 & 11 & 10 & 8 & 45 \\
\hline & $(\%)$ & (67) & (67) & $(92)$ & (83) & (67) & (75) \\
\hline \multirow{4}{*}{$T 2$} & Average bid ${ }^{\mathrm{a}}$ & 69.6 & 73.7 & 74.3 & 85 & 86.3 & \\
\hline & Average $r^{\mathrm{a}}$ & 0.94 & 1.23 & 1.46 & 0.9 & 1.3 & 1.17 \\
\hline & \#overbidders $^{\mathrm{c}}$ & 7 & 9 & 2 & 7 & 4 & 29 \\
\hline & $(\%)$ & (58) & (75) & (17) & $(58)$ & (33) & $(48)$ \\
\hline \multirow{4}{*}{$\begin{array}{l}\text { Column } \\
\text { total }\end{array}$} & RNNE & 66.7 & 75 & 80 & 83.3 & 88.9 & \\
\hline & Average $r^{\mathrm{a}}$ & 0.87 & 1.04 & 1.13 & 0.94 & 1.34 & 1.06 \\
\hline & \#overbidders $^{\mathrm{b}}$ & 22 & 25 & 18 & 19 & 12 & 96 \\
\hline & $(\%)$ & (65) & (69) & $(50)$ & (53) & (35) & (55) \\
\hline
\end{tabular}

a The arithmetic mean of subjects' average bids and the thus estimated individual risk preference parameter for given market size $N$ are recorded.

b $N$ indicates the market size, subjects competed with $N-1$ computerized bids.

c Subjects were classified according to their mean bid as overbidders or underbidders. The number of subjects is recorded whose average bid was above (overbidder) the RNNE; the average bids of the remaining subjects for given market-size were below the RNNE (underbidders). Relative numbers are recorded in parenthesis below the absolute numbers for each session.

bidder against the alternative hypothesis that overbidders are more frequent $(T 0: p=0.99$; $T 2: p=0.84$ ). ${ }^{15}$ The relative frequency of overbidders in $T 0$ was $41 \%$ (the $95 \%$ confidence band extends from 28 to 54\%) and in $T 248 \%$ (the $95 \%$ confidence band extends from 36 to $61 \%$ ), respectively. ${ }^{16}$

CRRAM predicts that submitted bids should be constant, i.e., that they do not change from one auction to the next if the resale value is the same. As reported below (see Table 4), subjects changed their consecutive bids in 87 percent of all observations. Still we might believe that subjects bid according to CRRAM up to some error term. Taking a subject's average bid as the reference bid, we constructed a test on the individual's bid sequence: a positive sign designated an above-average bid; a negative sign designated a below-average bid. Table 3 surveys the results of two-tailed one-sample runs tests of the null hypothesis that the sequence of a subject's bids changed by chance from above to below the mean and vice versa. The first (second) column indicate the number of subjects whose consecutive bids changed less (more) frequently than expected from one side of the average bid to the other. The data of 153 subjects (88\%) exhibit

15 The Wilcoxon signed ranks test conducted on the total of 174 individual risk preference parameters (returning a $p$-value of $p>0.70$ ) accepts the null hypothesis that the risk preference parameter is as likely greater as it is smaller than 1 .

16 The numbers recorded in Table 2 might hint at a negative correlation between $N$ and overbidding in treatments $T 0$ and $T 2$. The literature suggests that such a decline might occur in case of decreasing expected payoffs (Dyer et al., 1989). As we observe a positive correlation between $N$ and the number of overbidders for $T 1$, we are confident that in our data the issue is of minor relevance. 
Table 3

Number of subjects with less or more runs of overbidding or underbidding than randomly expected

\begin{tabular}{|c|c|c|c|}
\hline Treatment & $\begin{array}{l}\text { Less runs than expected } \\
\text { (significantly less) }^{\mathrm{b}}\end{array}$ & 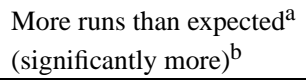 & $\begin{array}{l}\text { Wilcoxon test } Z^{\mathrm{c}} \\
(p \text {-value })\end{array}$ \\
\hline$T 0$ & $\begin{array}{c}49 \\
(32)\end{array}$ & $\begin{array}{c}5 \\
(2)\end{array}$ & $\begin{array}{l}-5.77 \\
(0.00)^{*}\end{array}$ \\
\hline$T 1$ & $\begin{array}{l}55 \\
(41)\end{array}$ & $\begin{array}{c}5 \\
(1)\end{array}$ & $\begin{array}{c}-5.64 \\
(0.00)^{*}\end{array}$ \\
\hline$T 2$ & $\begin{array}{c}49 \\
(30)\end{array}$ & $\begin{array}{l}11 \\
(1)\end{array}$ & $\begin{array}{c}-6.43 \\
(0.00)^{*}\end{array}$ \\
\hline Total & $\begin{array}{c}153 \\
(103)\end{array}$ & $\begin{array}{l}21 \\
(4)\end{array}$ & $\begin{array}{r}-10.38 \\
(0.00)\end{array}$ \\
\hline
\end{tabular}

a Outcomes of a two-sided one-sample runs test of the null hypothesis that the consecutive bids spread randomly around the average bid against the alternative that they do not. The number of subjects is recorded who changed their bids from below the average bid to above the average bid less (respectively more) frequently than expected by chance.

b Runs were significantly less/more frequently $(\alpha=0.05)$ than expected.

c Wilcoxon signed ranks test results (approximately standard normally distributed) of the null hypothesis that the outcomes of the runs test involve less runs than expected as likely as more runs than expected.

* Significant at $\alpha=0.05$.

less runs than expected, for 103 subjects (59\%) significantly less than expected at the $\alpha=0.05$ level of significance. The individual test results (not detailed here) were next used to test the null hypothesis that more runs are equally likely than less runs. A two-tailed Wilcoxon signed ranks test rejects $(p=0.00)$ highly significantly the null hypothesis for each treatment; its results are reported in the third column of Table $3 .{ }^{17}$

On the basis of our data we reject the CRRAM of bidding: First, subjects did not submit always the same bid nor did they bid according to CRRAM up to an error-term. Secondly, the reported risk preference parameters and results of under- and over-bidding do not support the implicit hypothesis of CRRAM that information feedback do not affect the subjects' bidding behavior in FPA. The data provide evidence that the behavior is influenced significantly by the information feedback conditions of the experiment: although treatments were identical up to the on-screen information about the highest bid of the computerized competitors they yield significantly different results. In what follows, we provide an explanation of the disparity of bidding behavior in treatments $T 0-T 2$ by means of a bidding dynamics analysis.

\section{Bidding dynamics analysis}

In the economic theory on FPA, in the RNNE as much as in the CRRAM, bids are linear functions of resale values. From the FPA experiment of Selten and Buchta (1994) it was reported that bid functions were usually non-linear and changing over the course of the experiment; quite often non-monotonous bid functions were observed. In their experiment a subject's task was to submit a bid function instead of a bid in 50 auction markets. They found in 35 percent of the observations that the bid functions were changed from one to the next auction. The bidding dynamics in their data could be explained to a good extent by learning direction theory. In the following subsection, learning direction theory will be reviewed and subsequently applied to the experimental data.

17 We conducted the same test for the reference bid equal to the RNNE (not detailed here). The null-hypothesis that subjects bid according to RNNE up to some error-term was rejected, too. 


\subsection{Learning direction theory and its implications}

The basic idea of learning direction theory goes back to Selten and Stoecker (1986). They applied it to data from the repeated prisoners' dilemma supergame. Since, it has been supported by the data of diverse experiments. ${ }^{18}$ In the review of learning direction theory we follow Selten and Buchta (1994): Learning direction theory is a qualitative behavioral theory based on bounded rationality. As an illustration of the theory, Selten and Buchta (1994) proposed the example of a marksman who shoots an arrow to hit a trunk. If the arrow misses the trunk to one side the marksman shifts the bow in the direction of the other side when he gives it another try. The marksman in the example draws qualitative conclusions from his information feedback and adjusts his behavior according to a causal relationship: if he misses, for instance, to the right he concludes that he could have got closer to his target if he had directed the arrow more to the left. This line of reasoning links to ex post rationality, it asks whether a different action might have produced a better result. Learning direction theory does not bring on a full-fledged behavioral model; it only makes predictions about tendencies of qualitative adjustment. It concerns the direction of a change rather than its size. A possible quantification of learning direction theory is provided in the next subsection. However, consider now the application of this theory to our FPA experiment. Let $b$ denote a subject's bid and $p$ denote the winning bid (i.e., the price) in the auction. Subjects could be in one of the following two experience conditions with respect to the preceding period:

(1) Successful bid condition: $b=p$.

(2) Lost opportunity condition: $b<p$.

In the experience condition of a successful bid, a subject won the preceding auction. Nevertheless, he might have received a greater payoff by submitting a lower bid. Similarly, in the lost opportunity condition the subject did not win the auction, but he could have won the auction by submitting a higher bid. Therefore, learning direction theory implies the bid change hypothesis that after a successful bid a subject tends to decrease his bid, while after experiencing a lost opportunity the subject tends to increase his bid.

Table 4 records the number of bid changes, i.e. increases or decreases of the bid from one auction to the next. Changes are listed separately according to subjects' experience condition of a successful bid or a lost opportunity in the preceding auction. A first observation reveals that in 87 percent of all observations subjects changed their bids from one auction to the following one; this finding contradicts the predictions of both the CRRAM and the RNNE which suggest constant bidding. In every treatment we observed that over 60 percent of bid changes go in the direction predicted by the bid change hypothesis and about 25 percent in the opposite one. A bidchange in the predicted direction, hence, occurred 2.4 times as often as an unpredicted one.

It appears to be interesting how many subjects behaved according to the bid change hypothesis: In determining the share of these subjects we proceeded similarly to Selten et al. (2005). A simple comparison of the relative frequencies of bid changes in the direction indicated by learning direction theory and in the opposite direction may be misleading. Random bidding results as well as learning direction theory in a preponderance of lower bids after high bids and higher bids after low bids. In order to generate an appropriate null hypothesis we ran 1000 simu-

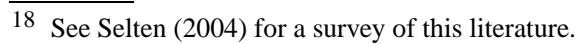


Table 4

Absolute (relative) $)^{\mathrm{a}}$ frequencies of bid changes in auctions 2-100

\begin{tabular}{|c|c|c|c|c|c|}
\hline Treatment & Experience condition & Bid decrease \# (\%) & Bid increase \# $(\%)$ & Unchanged bid \# (\%) & Row total \\
\hline \multirow[t]{4}{*}{$T 0$} & \multirow[t]{2}{*}{ Successful bid } & 1447 & 599 & 311 & 2357 \\
\hline & & $(61)$ & $(25)$ & (13) & (44) \\
\hline & \multirow[t]{2}{*}{ Lost opportunity } & 842 & 1785 & 362 & 2989 \\
\hline & & (28) & $(60)$ & (12) & $(56)$ \\
\hline \multirow[t]{4}{*}{$T 1$} & \multirow[t]{2}{*}{ Successful bid } & 1932 & 882 & 450 & 3264 \\
\hline & & (59) & (27) & (14) & $(55)$ \\
\hline & \multirow[t]{2}{*}{ Lost opportunity } & 571 & 1753 & 352 & 2676 \\
\hline & & (21) & (66) & (13) & $(45)$ \\
\hline \multirow[t]{6}{*}{$T 2$} & \multirow[t]{2}{*}{ Successful bid } & 1771 & 746 & 321 & 2838 \\
\hline & & $(62)$ & (26) & (11) & (48) \\
\hline & \multirow[t]{2}{*}{ Lost opportunity } & 739 & 1953 & 410 & 3102 \\
\hline & & (24) & (63) & (13) & $(52)$ \\
\hline & \multirow[t]{2}{*}{ Column total } & 7302 & 7718 & 2206 & 17226 \\
\hline & & (42) & (45) & (13) & (100) \\
\hline
\end{tabular}

${ }^{a}$ In the first three columns relative frequencies relate to the row total, in the last column relative frequencies relate to the total of observations in the respective treatment.

lations in which the sequence of the competitors' highest bids was randomly permuted, but the subject's submitted bid sequence was kept fixed. For each of these 1000 simulations we calculated the relative frequency of bid changes under the counterfactual assumption that the permuted sequence of the competitors' highest bids was observed. Let $M$ be the average of these relative frequencies and let $R$ be the relative frequency of bid changes conforming to learning direction theory actually observed in the experiment. The surplus $S=R-M$ measures the extent to which the observations support learning direction theory after the exclusion of mere random effects. We made the following observation: for 160 subjects $(92 \%)$ we found a positive $S>0$; as maximum surplus we observed 0.48 and the average of positive surpluses was $0.18 .{ }^{19}$ In other words, ninety-two percent of experimental subjects behaved more frequently than could be expected by chance in accordance with learning direction theory. The Wilcoxon signed ranks test of the null hypothesis that the mean surplus in the population of subjects is equal to zero, i.e., $\bar{S}=0$, is rejected ( $p=0.00$ ) in favor of the alternative hypothesis of $\bar{S}>0$.

Table 4 provides a key understanding of the driving forces behind the overbidding we observed in treatment $T 1$ of the experiment. Note first that in 59 percent of observations the bid decreased after a successful bid. Secondly, in 66 percent of observations the bid increased after a lost opportunity. Selten and Buchta (1994, p. 13), who made a similar observation under comparable feedback conditions, remarked that the impulse that a subject received was '... much clearer in the lost opportunity condition. ${ }^{20}$ We constructed a test-statistic (to be used in all tests of this paragraph) by calculating for each subject (and each experience condition) the relative frequency of bid changes he or she realized in accordance with the bid change hypothesis. With respect

\footnotetext{
19 On the other hand, we observed a negative surplus $S<0$ for 14 subjects (8\%). The minimum surplus we observed was -0.09 and the average of the negative surpluses was -0.03 . Less than $5 \%$ (i.e., 8 out of 174) of all subjects violated the bid change hypothesis at least in one direction. One subject decreased his bids more frequently than he increased them after not winning the auction, six other subjects increased their bids more frequently than they decreased them after winning the auction, and one subject's behavior was at odds with the bid change hypothesis in both directions.

20 Comparable results were reported by Cason and Friedman $(1997,1999)$ who use both qualitative and quantitative directional learning to explain overbidding in two-sided auctions.
} 
to $T 1$ a two-tailed Wilcoxon signed ranks test rejected $(p=0.00)$ the null hypothesis that it is equally likely to observe a higher relative frequency of bid increases after a lost opportunity than of bid decreases after a successful bid. Thirdly, notice further that in $T 0$ the relative frequency of a bid increase after a lost opportunity was equally high $(p=0.37)$ as the relative frequency of a bid decrease after a successful bid. ${ }^{21}$ Moreover, in $T 2$ a bid decrease after a successful bid was not significantly more likely $(p>0.25)$ than an increase after a lost opportunity. Fourthly, note that a bid increase after a lost opportunity in $T 1$ was more likely than in $T 0$ (and the impulse was clearer in $T 1) .{ }^{22}$ Fifthly and finally, the bid decrease after a successful bid was more likely (although not at the $\alpha=0.05$-level of significance) in $T 2$ than in $T 1$ (and the impulse was clearer in $T 2) .{ }^{23}$ On the basis of these observations we conclude that subjects react more frequently to an impulse when it implies clear feedback information in terms of foregone payoff. The feedback condition in $T 1$ was asymmetrical since the highest bid of the competitors was revealed only if the subject submitted a lower bid. In the experience condition of a successful bid, conversely, the impulse was ambiguous: the subject did not know whether he also could have won the auction by submitting a lower bid; in hindsight, he did not receive clear information. Since we do not observe a similar pattern in the symmetrical information treatments $T 0$ and $T 2,{ }^{24}$ we conclude that the asymmetrical information with respect to impulse clarity implied a drift towards higher bids in the treatment $T 1$.

\subsection{Impulse balance theory}

In a recent paper, Selten et al. (2005) proposed impulse balance theory, which makes possible quantitative predictions of the long-run effects of learning direction theory. Impulse balance theory is mainly applicable in economic situations in which clear impulses are provided so that, in hindsight, the ex post-rational choice can be exactly determined. It assumes that impulses that involve greater gains are relatively more important. Ex post rationality results in an upward or downward impulse in accordance with learning direction theory. Impulse balance theory proposes the impulse balance point at which upward and downward impulses cancel out in the long run. Note that impulse balance theory builds on the payoff space of a bidder rather than on his message space. ${ }^{25}$

Consider the FPA situation implied by treatment $T 2$. Let $x$ denote the highest bid of the competitors; and as before, let $b$ denote the agent's bid and $p$ the winning bid. A successful bid implies that the agent won the preceding auction. Winning the auction produced a profit, but also an opportunity cost. The agent could have also won the auction by submitting a bid equal to the highest bid of the competitors. In accordance with impulse balance theory, in the successful bid condition the agent receives a downward impulse equal to the difference between the bid and the highest bid of the competitors. Conversely, a lost opportunity implies that the agent did not win

\footnotetext{
21 This result is not generally confirmed for all considered market sizes $N$. For $N=9$, bid decreases after a successful bid are significantly more likely than bid increases after a lost opportunity.

22 A two-tailed Mann-Whitney test rejects $(p=0.01)$ the null hypothesis that bid increases in the lost opportunity condition occur with equal likelihood in $T 1$ and in $T 0$.

23 A two-tailed Mann-Whitney test accepts $(p=0.18)$ the null hypothesis that in $T 1$ and $T 2$ bid decreases in the successful bid condition occur with equal likelihood.

24 In $T 0$, ambiguity about the winning bid existed in both experience conditions; in $T 2$ there was a clear impulse in both experience conditions.

25 Recall Harrison's (1989) critique, here.
} 
the preceding auction. Not winning the auction produced no payoff. However, if the agent had submitted a bid equal to the highest bid of his competitors he would have won the auction. In the lost opportunity condition, impulse balance theory implies an upward impulse equal to the difference between the agent's resale value $v$ and the highest bid of the competitors. Following Selten et al. (2005), the downward impulse $a_{-}(\cdot)$ and the upward impulse $a_{+}(\cdot)$ can be described as follows:

$$
\begin{aligned}
& a_{-}(b, x)=\max (0, b-x), \\
& a_{+}(b, x)= \begin{cases}v-x & \text { if } x>b, \\
0 & \text { otherwise. }\end{cases}
\end{aligned}
$$

Define

$$
\begin{aligned}
& A_{-}(b)=E\left[a_{-}(b, x)\right], \\
& A_{+}(b)=E\left[a_{+}(b, x)\right],
\end{aligned}
$$

then the impulse balance point $b^{*}$ is defined by the impulse balance equation:

IBE: $A_{-}\left(b^{*}\right)=A_{+}\left(b^{*}\right)$.

The impulse balance point (hereafter IBE) is uniquely determined. This is easily seen by noting that the left hand side of the impulse balance equation increases in $b^{*}$, whereas the right hand side decreases in $b^{*}$; and for $b^{*}=v$ the left hand side is greater than the right hand side, while for $b^{*}=0$ the left hand side is smaller than the right hand side.

\subsection{Impulse balance points}

Let the number of competitors' bids be denoted by $n$, such that $n=N-1$, and let the resale value $v$ be normalized to one, i.e., $v=1$, such that the competitors' bids are uniformly, identically and independently distributed over the interval from 0 to 1 . Let $F(X<x)=x^{n}$ denote the cumulative probability that all $n$ competitors' bids are smaller than some real number $x$, and let $f(x)=n x^{n-1}$ denote its density, we can write the impulse balance equation for treatment $T 2$ as follows:

$$
\begin{aligned}
& A_{-}\left(b^{*}\right)=A_{+}\left(b^{*}\right), \\
& \int_{-\infty}^{+\infty} f(x) a_{-}\left(b^{*}, x\right) \mathrm{d} x=\int_{-\infty}^{+\infty} f(x) a_{+}\left(b^{*}, x\right) \mathrm{d} x, \\
& \int_{0}^{b^{*}} n x^{n-1}\left(b^{*}-x\right) \mathrm{d} x=\int_{b^{*}}^{1} n x^{n-1}(1-x) \mathrm{d} x, \\
& b^{* n+1}-\frac{n}{n+1} b^{* n+1}=1-\frac{n}{n+1}-b^{* n}+\frac{n}{n+1} b^{* n+1} . \\
& \mathrm{IBE}-\mathrm{T} 2: \quad 0=\frac{1}{n+1}-b^{* n}+\frac{n-1}{n+1} b^{* n+1}, \\
& 0=b^{* n+1}-\frac{n+1}{n-1} b^{* n}+\frac{1}{n-1} \text {. }
\end{aligned}
$$


Since the impulse balance of $T 2$, as per (7), involves no parameter, we can easily calculate the impulse balance points for each market size of our experiment. ${ }^{26}$ In treatments $T 0$ and $T 1$, however, the impulses are not clear in at least one experience condition such that the subject can only count the impulses in each direction. If the bidder chooses the bid $b$ then the probability of a downward impulse is $b^{n}$ and the probability of an upward impulse is $1-b^{n}$. However, the subject may attach a different importance to downward and upward impulses. Therefore, we introduce a parameter $\lambda>0$, the downward impulse multiplier, and write the impulse balance equation as follows ${ }^{27}$ :

$$
\lambda b^{* n}=1-b^{* n} .
$$

The downward impulse multiplier can be interpreted as an indicator of the importance of a downward impulse relatively to an upward one. If more importance is put on downward impulses then fewer downward impulses can counterweigh more upward impulses. For example, if we have $\lambda=2$ the expected upward impulse must be double the expected downward impulse at the impulse balance. In other words, one unit of downward impulse would have the same weight as two units of upward impulse. In this sense $\lambda$ is the relative importance of downward impulses. Rearranging Eq. (8), we get an explicit formulation for the impulse balance bids of $T 0$ and $T 1$ :

$$
\text { IBE- } T 0, T 1^{28}: \quad b^{*}=\sqrt[n]{\frac{1}{1+\lambda}} .
$$

To determine the impulse balance points of $T 0$ and $T 1$, as per (9), we have to proceed by estimating the downward impulse multiplier from the data. For each subject $i$ we determined the multiplier $\lambda_{i}$ according to the average bid of the subject and took the median of these individual multipliers as an estimation of $\lambda$. Thus, the estimator of the downward impulse multiplier in $T 0$ was $\lambda_{\text {median }}(T 0)=1.74$; and in $T 1$ correspondingly $\lambda_{\text {median }}=1.01 .^{29}$ For $T 1$ the estimate of the downward impulse multiplier indicates that subjects weigh downward and upward impulses equally. It suggests that subjects use a count heuristic, i.e., they count upward and downward impulses. At least at first glance there seems to be a discrepancy between this result for treatment $T 1$ and earlier findings summarized by Table 4 . There, the relative frequencies of upward and downward impulses for $T 1$ are 0.55 and 0.45 respectively. However, the estimate $\lambda_{\text {median }}(T 1)=1.01$ is the median of all estimates for individual subjects and does not necessarily reflect aggregate behavior. Therefore our conclusions about differences between the successful bid and the lost opportunity conditions with respect to the conformance to learning direction theory do not necessarily hold for the median subject. For $T 0$ the estimate of the downward impulse multiplier indicates that one unit downward impulse weighs 1.74 units of upward impulse. This would imply that subjects were more strongly motivated by a downward impulse than by an upward impulse. In fact, we lack an intuition why subjects should weigh downward impulses so much. Therefore, it is unclear to us whether impulse balance theory should be applied to this treatment. In principle, we would expect subjects of $T 0$ to use a count heuristic, too. The theory does not

\footnotetext{
26 It should be noted that the impulse balance point calculated here is not the impulse balance. It is only the prediction of a subject's action if all other agents behave according to the RNNE.

27 Ockenfels and Selten (2005) use a similar approach with one parameter, the estimate of which averages $\lambda=0.34$. In their design, subjects receive a value which they maintain for five FPA. Subjects are matched subsequently in markets of size $N=2$ facing a different opponent in every round.

28 Note from the equation that at the impulse balance the bid is the lower the higher the downward impulse multiplier is.

29 (As in Fn. 10 and Fn. 13) Individual statistics, including downward impulse multiplier, are listed in Table A.1 in Appendix A.
} 
allow us to draw any conclusion why we observe this disparity between the two treatments. The only difference is that in $T 0$ subjects receive no quantitative information feedback about how far the bid has been from the right decision while in $T 1$ they receive clear impulses at least in one direction. Apparently this lack of impulse clarity produces a more uncertain and more erratic behavior; the variations of bids between two consecutive auctions are greater in $T 0$ than in $T 1 .^{30}$ To sum up, although the qualitative behavior is in harmony with learning direction theory, we cannot rationalize the quantitative behavior of $T 0$. We hope to unravel this issue in the future.

Table 5 gives an overview over the determined impulse balance points for the different treatments. In contrast to the RNNE and the CRRAM, impulse balance theory predicts different impulse balance points for each feedback condition. Note that only the impulse balance points for $T 1$ exceed the RNNE. Table 5 surveys, also, the predictions of CRRAM which were calculated by the overall median of the individual risk preference parameters, $r_{\text {median }}=0.93 .{ }^{31}$

In order to compare the fit provided by these competing theories we measured the distance of each subject's average bid to the impulse balance point, the RNNE and the CRRAM. Table 6 records separately for each treatment the number of subjects whose average bid was closest to either predictor. Subjects' average bids are best described in 54 percent of all observations by the impulse balance points, in 15 percent and 31 percent by RNNE and by CRRAM, respectively. ${ }^{32}$ However, we should concede that impulse balance theory is not yet a fully satisfactory theory. ${ }^{33}$ It might not be better than RNNE or CRRAM in all circumstances; we cannot tell because the statistical evidence is missing. Nevertheless, it must be seen as a reasonable benchmark since it is

Table 5

Impulse balance points and the RNNE for each market size and treatment

\begin{tabular}{|c|c|c|c|c|c|}
\hline \multirow[t]{2}{*}{ Treatment } & \multicolumn{5}{|l|}{$N^{\mathrm{a}}$} \\
\hline & 3 & 4 & 5 & 6 & 9 \\
\hline IBP for $T 0$ & 60.5 & 71.5 & 77.8 & 81.8 & 88.2 \\
\hline IBP for $T 1$ & 70.5 & 79.2 & 84 & 86.9 & 91.6 \\
\hline IBP for $T 2$ & 65.3 & 73.4 & 78.4 & 81.8 & 87.7 \\
\hline RNNE & 66.7 & 75 & 80 & 83.3 & 88.9 \\
\hline CRRAM $^{\mathrm{b}}$ & 68.3 & 76.3 & 81.1 & 84.3 & 89.6 \\
\hline
\end{tabular}

a $N$ indicates the market size, subjects competed with $N-1$ computerized bids.

b CRRAM predictions corresponding to the median risk preference parameter.

\footnotetext{
30 We compared the sum of individual squared changes between rounds in $T 0$ with those of $T 1$. The deviations in $T 0$ were greater than in $T 1$ for each market size $N$. The Mann-Whitney test yields the following outcomes of $p=$ $\{0.02,0.44,0.20,0.59,0.01\}$ for $N=\{3,4,5,6,9\}$, respectively.

31 In order to make a general point prediction we need to fix an $r$. As pointed out above, the risk preference parameter is individually different in the CRRAM. Taking the median observation neglects these differences.

32 The CRRAM and the RNNE jointly provide a better fit than the IBP in 46 percent of observations. If we adopted individual preference parameters as we should according to the assumptions of the CRRAM and not the median preference parameter as we do, the fit of the CRRAM would be 100 percent in this exercise. As a matter of fact, the fit of the CRRAM is not $100 \%$. It fails to explain the treatment effect between $T 1$ on one side and $T 0$ and $T 2$ on the other, and it ignores the learning behavior in the data. Hence, assuming individual risk preference parameters obviously immunizes the CRRAM against criticism.

33 A referee has drawn our attention to the apparent effect between information feedback and market size $N$; there are no significant treatment effects in overbidding between treatments with $N=3$ and 4 (see footnote 18 and Table 2). In contrast to this evidence, the impulse balance points do suggest differences between treatments. Where the discrepancy between the data and the theoretical prediction comes from, we do not know. In fact, we cannot exclude that there is still too much noise in the data as we account only for a small number of independent observations per $N$ (i.e., $\# 12$ ).
} 
Table 6

Number of subjects whose average bids were closest to the respective predictor (RNNE, CRRAM, Impulse balance point)

\begin{tabular}{lccc}
\hline Treatment & RNNE $(r=1)^{\mathrm{a}} \#(\%)$ & CRRAM $(r=0.93)^{\mathrm{a}} \#(\%)$ & Impulse balance point $^{\mathrm{a}} \#(\%)$ \\
\hline$T 0$ & 6 & 20 & 28 \\
& $(11)$ & $(37)$ & $(51)$ \\
$T 1$ & 15 & 8 & 37 \\
& $(25)$ & $(13)$ & $(61)$ \\
$T 2$ & 5 & 26 & 29 \\
& $(8)$ & $(43)$ & $(48)$ \\
Total & 26 & 54 & 94 \\
& $(15)$ & $(31)$ & $(54)$ \\
\hline
\end{tabular}

a Absolute numbers recorded in every first row refer to the subjects for whom the distance of the individual average bid from the Impulse balance point, RNNE or CRRAM was smallest, respectively. Relative numbers in every second row are recorded in parenthesis.

based on learning direction theory, which has been soundly supported by the data. The CRRAM and the RNNE, on the other hand, are not linked to any learning theory and lack an explanation of how subjects approach the equilibrium. ${ }^{34}$

\section{Summary}

We designed a first-price sealed-bid auction experiment to test the predictions of the CRRAM and the RNNE in an environment in which subjects faced objective probabilities with respect to the behavior of their competitors. Competitors' bids were randomly drawn by the computer, such that agents who exhibit constant relative risk aversion would maximize their utility by bidding as predicted in the CRRAM (2). Cox et al. (1982a, 1982b, 1983a, 1983b, 1984, 1985a, 1985b, 1987, 1988) developed the CRRAM to explain the observed overbidding regularity in FPA experiments in which the winning bid was revealed after each auction. Overbidding above the RNNE was not a consistent pattern of our experimental data. In two out of three treatments subjects' average bids were below rather than above the RNNE. Only under standard information feedback of FPA experiments, i.e., price revelation, we observed overbidding. Thus, the data provide evidence that the feedback conditions can significantly influence behavior in experiments with computerized bidders. ${ }^{35}$ Subjects' qualitative bidding behavior did not support the CRRAM, either, since it predicts degenerate behavior. Subjects did neither bid constantly nor did they vary the bid up to an error-term around their average bid. The CRRAM must therefore be rejected.

\footnotetext{
34 Actually, such learning stories were proposed for the FPA already in the discussion to Harrison's critique by Friedman (1992, p. 1377): 'An alternative direction to CSW's generalized preferences arises from a learning and adjustment story. Suppose typical bidders in the CSW auctions begin with the rule of thumb "bid $x$ percent of value," where $x$ is exogenous, and learn by trial and error to adapt $x$ toward its Vickrey value $x^{*}$ (... or perhaps toward some risk-averse analog ...).' There are numerous papers on learning in games that made the general point that learning explains behavior better than simple equilibrium point predictions. Camerer (2003) provides a broad survey of such literature. It would be an interesting research task to contrast these learning models with respect to their convergence properties in the experimental FPA.

35 In a follow up study to the present work, which used within subject variation, Neugebauer and Perote (2005) found similar evidence in an interactive FPA experiment of market size $N=7$. They report that subjects did not overbid the RNNE as long as they did not receive any information feedback, but the very same subjects did overbid when price information feedback was introduced. An impact of feedback conditions on behavior in FPA was already observed in the classic paper by Isaac and Walker (1985).
} 
The data could be explained qualitatively by learning direction theory (Selten and Buchta, 1994) which goes back to Selten and Stoecker (1986). The bidding dynamics of 92 percent of the subjects were in line with the bid change hypothesis derived from learning direction theory. Comparing the individual behavior in the three feedback conditions of the experiment, we found that subjects reacted significantly more frequently to an impulse (according to the predictions of learning direction theory) if it was quantitatively clear in terms of foregone payoff. Thus, the asymmetry of information feedback with regard to the greatest competitors' bid in the standard feedback condition of FPA apparently produced an upward drift that led to overbidding in treatment $T 1$.

In order to provide a quantitative explanation of the data we applied impulse balance theory of Selten et al. (2005). Impulse balance theory is a static equilibrium concept that builds on the payoff space of agents and makes point predictions of the long-run behavior on the basis of learning direction theory. Differing from the RNNE, we determined distinct impulse balance points under each of the three feedback conditions of the experiment; the impulse balance points take the information differences into account. Subjects' average bids were closest to the impulse balance points in more than 50 percent of observations compared to the RNNE and the CRRAM. Impulse balance theory seems to provide good alternative predictors to the Nash equilibria for behavioral studies.

\section{Acknowledgments}

We are indebted to Elisabetta Venezia for her translation of the instructions into Italian and to Andrea Morone for his generous help with the conduct of the experiment. We thank Dan Friedman, two referees, the associated editor and seminar participants at Max-Planck-Institute Jena, Caltech, University Kiel and University Hannover for helpful comments.

\section{Appendix A}

\section{A.1. Proposition}

Assume that a bidder has a resale value equal to $v=1$ for the object to be auctioned, and let the bids of $N-1$ competitors be identically and independently drawn from a continuous uniform distribution ranging from 0 to 1 . Assume the bidder's utility function is given by $u(y)=(y)^{r}$, where $y$ is the bidder's income and $r>0$ denotes the bidder's risk preference parameter. The following statements hold:

(i) The bidder's bid equals the Nash equilibrium bid of the CRRAM.

(ii) For $r=1$ (risk-neutrality), the bidder's bid is equal to the RNNE bid.

Proof. The probability that the bidder's bid $b$ exceeds the bid of every competitor is $b^{N-1}$. Therefore the bidder's expected utility $U(v, b)$ for bidding $b$ is as follows:

$$
U(v, b)=u(v-b) b^{N-1}=(v-b)^{r} b^{N-1} .
$$

Differentiating with respect to $b$ yields the first order condition.

$$
\frac{\partial U(v, b)}{\partial b}=-r(v-b)^{r-1} b^{N-1}+(v-b)^{r} b^{N-2}(N-1)=0 .
$$


This yields $-r(v-b)^{r-1} b+(v-b)^{r}(N-1)=0$.

It follows that the bidder who faces an Arrow-Pratt constant relative risk aversion parameter $1-r$ submits a bid equal to the Nash equilibrium bid in the CRRAM, (2):

$$
b^{*}(v, r)=\frac{N-1}{N-1+r} \cdot v .
$$

If the bidder is risk-neutral the bid is equal to the one in the RNNE, (1):

$$
b^{*}(v, 1)=\frac{N-1}{N} \cdot v .
$$

It remains to show that (2) is sufficient for utility maximization, i.e. the second derivative of the utility function is negative at $b^{*}(v, r)$. We differentiate $(*)$ to obtain

$$
\frac{\partial^{2} U}{\partial b^{2}}=(v-b)^{r-2} b^{N-3} f(\nu, b)
$$

where $f(v, b)=r(r-1) b^{2}-2 r(N-1)(v-b) b+(N-1)(N-2)(v-b)^{2}$. Note, we have $v=1$, such that $v-b^{*}=r /(N-1+r)>0$. It remains to show that $f\left(1, b^{*}\right)<0$.

$$
\begin{aligned}
f\left(1, b^{*}\right) & =\frac{N-1}{(N-1+r)^{2}}\left[\left(r^{2}-r\right)(N-1)-2 r^{2}(N-1)+(N-2) r^{2}\right] \\
& =\frac{N-1}{(N-1+r)^{2}}\left[-r(N-1)-r^{2}\right]<0 .
\end{aligned}
$$

This completes the proof. Hence, $b^{*}(1, r)$ maximizes expected utility for all $r>0$.

\section{A.2. Instructions}

In the experiment you will participate in 100 auctions.

At the beginning of each round, $(N-1)$ numbers between 0 and 100 are drawn randomly and independently (i.e., in each draw every number between 0 and 100 is equally likely). ${ }^{36}$

These numbers represent the $(N-1)$ bids of your competitors in the auction. Without knowledge of the others' bids you will be asked to submit your bid, which can be any number between 0 and 100. In each round, the highest bid (including your own) determines the market price.

Your bid determines your round payoff as follows:

If your bid is equal to the price, you will receive the difference between 100 and your bid (i.e., payoff $=100-$ price) expressed in ECU (experimental currency units), otherwise you will receive nothing. The exchange rate will be $1 \mathrm{ECU}=5(N)$ ITL. At the end of the experiment you will be paid your accumulated payoff privately.

At the end of a round, you will be informed about

(1) (T0:) the auction price only if it is equal to your bid, $(T 1, T 2:)$ the auction price;

(2) (T2:) the highest bid submitted by your competitors; (Note: if you submit a bid equal to the highest bid of your competitors you win the auction without further notice.)

(3) your resulting round payoff;

(4) your accumulated payoff.

Furthermore, throughout the experiment you will receive on-screen information about all corresponding historical records.

36 For the instructional sessions $(N-1)$ was substituted accordingly to the session's number of computerized competitors $N-1=\{2,3,4,5,8\}$. Instructions were read aloud. Subjects were encouraged to ask questions in case of doubts. 
Table A.1

Subjects' first bids and individual statistics over 100 auctions

\begin{tabular}{|c|c|c|c|c|c|c|c|c|c|c|c|c|c|c|c|c|c|c|}
\hline \multirow[t]{2}{*}{$N^{\mathrm{a}}$} & \multirow[t]{2}{*}{ RNNE } & \multicolumn{6}{|c|}{$T 0^{\mathrm{b}}$} & \multicolumn{6}{|l|}{$T 1$} & \multicolumn{5}{|l|}{$T 2$} \\
\hline & & ID & 1st bid & Mean & Median & $\lambda_{i}$ & $r_{i}$ & ID & 1st bid & Mean & Median & $\lambda_{i}$ & $r_{i}$ & ID & 1st bid & Mean & Median & $r_{i}$ \\
\hline 3 & 66.7 & 1 & 85 & 76.8 & 80 & 0.7 & 0.61 & 55 & 21 & 80.4 & 85 & 0.55 & 0.49 & 115 & 62 & 71.6 & 72 & 0.79 \\
\hline 3 & 66.7 & 2 & 68 & 68.9 & 77 & 1.11 & 0.9 & 56 & 58 & 62.7 & 59 & 1.54 & 1.19 & 116 & 40 & 58.8 & 61 & 1.4 \\
\hline 3 & 66.7 & 3 & 78 & 63.9 & 65.5 & 1.45 & 1.13 & 57 & 78 & 78.9 & 80 & 0.61 & 0.54 & 117 & 21 & 51.3 & 55.5 & 1.9 \\
\hline 3 & 66.7 & 4 & 63 & 85.4 & 91 & 0.37 & 0.34 & 58 & 40 & 83.3 & 80 & 0.44 & 0.4 & 118 & 5 & 77.3 & 88 & 0.59 \\
\hline 3 & 66.7 & 5 & 50 & 72 & 80 & 0.93 & 0.78 & 59 & 55 & 78.9 & 80 & 0.61 & 0.54 & 119 & 56 & 78.1 & 81.5 & 0.56 \\
\hline 3 & 66.7 & 6 & 75 & 66.9 & 73 & 1.23 & 0.99 & 60 & 30 & 81 & 80 & 0.52 & 0.47 & 120 & 55 & 79.4 & 84 & 0.52 \\
\hline 3 & 66.7 & 7 & 100 & 76.2 & 80 & 0.72 & 0.63 & 61 & 48 & 86.3 & 88 & 0.34 & 0.32 & 121 & 90 & 86.1 & 90 & 0.32 \\
\hline 3 & 66.7 & 8 & 70 & 66.3 & 70 & 1.27 & 1.02 & 62 & 50 & 54.6 & 56 & 2.35 & 1.66 & 122 & 65 & 64.2 & 66.5 & 1.12 \\
\hline 3 & 66.7 & 9 & 60 & 69.7 & 70.5 & 1.06 & 0.87 & 63 & 60 & 64.5 & 63 & 1.4 & 1.1 & 123 & 50 & 76.9 & 79 & 0.6 \\
\hline 3 & 66.7 & 10 & 50 & 55.7 & 55 & 2.22 & 1.59 & 64 & 98 & 83.6 & 85 & 0.43 & 0.39 & 124 & 65 & 67.4 & 72.5 & 0.97 \\
\hline 3 & 66.7 & b & & & & & & 65 & 51 & 73.7 & 75 & 0.84 & 0.71 & 125 & 66 & 59.2 & 50 & 1.38 \\
\hline 3 & 66.7 & $\mathrm{~b}$ & & & & & & 66 & 58 & 56.8 & 56 & 2.1 & 1.52 & 126 & 55 & 64.5 & 65 & 1.1 \\
\hline 4 & 75 & 11 & 45 & 80.4 & 86.5 & 0.92 & 0.73 & 67 & 66 & 72.6 & 74.5 & 1.61 & 1.13 & 127 & 76 & 62.2 & 64.5 & 1.82 \\
\hline 4 & 75 & 12 & 50 & 69.1 & 76 & 2.03 & 1.34 & 68 & 68 & 76 & 78 & 1.28 & 0.95 & 128 & 85 & 82.5 & 84.5 & 0.64 \\
\hline 4 & 75 & 13 & 99 & 83.1 & 85 & 0.74 & 0.61 & 69 & 62 & 90.4 & 90 & 0.35 & 0.32 & 129 & 62 & 75.5 & 79 & 0.97 \\
\hline 4 & 75 & 14 & 70 & 82.6 & 82 & 0.77 & 0.63 & 70 & 48 & 70.1 & 74.5 & 1.9 & 1.28 & 130 & 69 & 54 & 55 & 2.55 \\
\hline 4 & 75 & 15 & 58 & 67.6 & 69 & 2.24 & 1.44 & 71 & 25 & 79.1 & 82 & 1.02 & 0.79 & 131 & 30 & 81.5 & 82 & 0.68 \\
\hline 4 & 75 & 16 & 66 & 81.7 & 82.5 & 0.83 & 0.67 & 72 & 65 & 72.6 & 72 & 1.61 & 1.14 & 132 & 27 & 75.3 & 83.5 & 0.98 \\
\hline 4 & 75 & 17 & 81 & 53.1 & 54.5 & 5.68 & 2.65 & 73 & 75 & 84.9 & 86 & 0.63 & 0.54 & 133 & 10 & 44.1 & 46.5 & 3.8 \\
\hline 4 & 75 & 18 & 72 & 67.8 & 71 & 2.21 & 1.43 & 74 & 70 & 78.7 & 78 & 1.05 & 0.81 & 134 & 65 & 81 & 85 & 0.7 \\
\hline 4 & 75 & 19 & 87 & 85.6 & 88 & 0.59 & 0.51 & 75 & 59 & 71.8 & 79.5 & 1.7 & 1.18 & 135 & 20 & 87.4 & 85.5 & 0.43 \\
\hline 4 & 75 & 20 & 58 & 75.1 & 83 & 1.36 & 0.99 & 76 & 65 & 82.1 & 81 & 0.81 & 0.66 & 136 & 11 & 77.8 & 80 & 0.85 \\
\hline 4 & 75 & 21 & 95 & 85.7 & 87 & 0.59 & 0.5 & 77 & 52 & 79.2 & 82 & 1.01 & 0.79 & 137 & 74 & 82.3 & 84 & 0.65 \\
\hline 4 & 75 & 22 & 88 & 83.9 & 87 & 0.69 & 0.58 & 78 & 65 & 77.4 & 79.5 & 1.16 & 0.88 & 138 & 90 & 80.4 & 81.5 & 0.73 \\
\hline 5 & 80 & 23 & 75 & 72.2 & 79 & 2.68 & 1.54 & 79 & 86 & 92.1 & 92 & 0.39 & 0.34 & 139 & 82 & 82.7 & 82.5 & 0.84 \\
\hline 5 & 80 & 24 & 87 & 81.2 & 87 & 1.3 & 0.92 & 80 & 85 & 83.9 & 86 & 1.02 & 0.77 & 140 & 88 & 68.8 & 67 & 1.81 \\
\hline 5 & 80 & 25 & 78 & 73.6 & 77 & 2.41 & 1.44 & 81 & 68 & 86.5 & 87 & 0.79 & 0.63 & 141 & 56 & 77 & 79 & 1.19 \\
\hline 5 & 80 & 26 & 70 & 75.7 & 75 & 2.05 & 1.29 & 82 & 90 & 91.5 & 92 & 0.43 & 0.37 & 142 & 50 & 79.1 & 80 & 1.06 \\
\hline 5 & 80 & 27 & 76 & 66.2 & 74 & 4.21 & 2.04 & 83 & 55 & 78.8 & 80 & 1.59 & 1.08 & 143 & 70 & 78 & 84 & 1.13 \\
\hline 5 & 80 & 28 & 78 & 84.6 & 85 & 0.95 & 0.73 & 84 & 55 & 85.4 & 89 & 0.88 & 0.68 & 144 & 90 & 78.2 & 80 & 1.11 \\
\hline 5 & 80 & 29 & 55 & 82.1 & 86 & 1.2 & 0.87 & 85 & 98 & 84.4 & 88 & 0.97 & 0.74 & 145 & 25 & 57.6 & 66.5 & 2.95 \\
\hline 5 & 80 & 30 & 54 & 63 & 65 & 5.35 & 2.35 & 86 & 85 & 88.3 & 88 & 0.64 & 0.53 & 146 & 10 & 74.3 & 85 & 1.39 \\
\hline
\end{tabular}


Table A.1 (continued)

\begin{tabular}{|c|c|c|c|c|c|c|c|c|c|c|c|c|c|c|c|c|c|c|}
\hline \multirow[t]{2}{*}{$N^{\mathrm{a}}$} & \multirow[t]{2}{*}{ RNNE } & \multicolumn{6}{|c|}{$T 0^{\mathrm{b}}$} & \multicolumn{6}{|l|}{$T 1$} & \multicolumn{5}{|l|}{$T 2$} \\
\hline & & ID & 1st bid & Mean & Median & $\lambda_{i}$ & $r_{i}$ & ID & 1st bid & Mean & Median & $\lambda_{i}$ & $r_{i}$ & ID & 1st bid & Mean & Median & $r_{i}$ \\
\hline 5 & 80 & 31 & 48 & 70.8 & 75.5 & 2.98 & 1.65 & 87 & 80 & 82.9 & 86 & 1.12 & 0.83 & 147 & 79 & 71.6 & 77 & 1.58 \\
\hline 5 & 80 & 32 & 89 & 87.2 & 89 & 0.73 & 0.59 & 88 & 60 & 89.5 & 91 & 0.56 & 0.47 & 148 & 50 & 59.3 & 58.5 & 2.74 \\
\hline 5 & 80 & 33 & 88 & 87.2 & 87.5 & 0.73 & 0.59 & 89 & 75 & 82.4 & 84 & 1.17 & 0.85 & 149 & 78 & 79.4 & 80 & 1.04 \\
\hline 5 & 80 & 34 & 56 & 79 & 85 & 1.57 & 1.06 & 90 & 60 & 84 & 87.5 & 1.01 & 0.76 & 150 & 45 & 85.3 & 95 & 0.69 \\
\hline 6 & 83.3 & 35 & 78 & 74.9 & 83 & 3.24 & 1.68 & 91 & 70 & 89.2 & 90 & 0.77 & 0.6 & 151 & 47 & 81.7 & 80.5 & 1.12 \\
\hline 6 & 83.3 & 36 & 65 & 80.1 & 90.5 & 2.03 & 1.24 & 92 & 80 & 84.3 & 85 & 1.35 & 0.93 & 152 & 11 & 82.7 & 83 & 1.05 \\
\hline 6 & 83.3 & 37 & 69 & 81.3 & 83.5 & 1.82 & 1.15 & 93 & 89 & 88.9 & 90 & 0.8 & 0.62 & 153 & 5 & 78.1 & 80 & 1.4 \\
\hline 6 & 83.3 & 38 & 56 & 76.5 & 80 & 2.82 & 1.53 & 94 & 90 & 80.3 & 85.5 & 2 & 1.22 & 154 & 83 & 78.1 & 80 & 1.4 \\
\hline 6 & 83.3 & 39 & 88 & 82.3 & 88 & 1.65 & 1.08 & 95 & 90 & 93.2 & 95 & 0.42 & 0.36 & 155 & 75 & 77.4 & 78 & 1.46 \\
\hline 6 & 83.3 & 40 & 80 & 84.8 & 86 & 1.28 & 0.9 & 96 & 88 & 93.5 & 97 & 0.4 & 0.35 & 156 & 57 & 90.4 & 93.5 & 0.53 \\
\hline 6 & 83.3 & 41 & 65 & 71 & 76 & 4.54 & 2.04 & 97 & 50 & 88 & 89 & 0.89 & 0.68 & 157 & 65 & 91.6 & 93 & 0.46 \\
\hline 6 & 83.3 & 42 & 87 & 83.1 & 87 & 1.52 & 1.02 & 98 & 65 & 81.4 & 85 & 1.8 & 1.14 & 158 & 75 & 92 & 93 & 0.43 \\
\hline 6 & 83.3 & 43 & 65 & 81.2 & 85 & 1.83 & 1.16 & 99 & 90 & 88.4 & 90 & 0.85 & 0.66 & 159 & 85 & 89.3 & 91 & 0.6 \\
\hline 6 & 83.3 & 44 & 80 & 87.4 & 88 & 0.96 & 0.72 & 100 & 85 & 89.7 & 92 & 0.72 & 0.58 & 160 & 75 & 88.3 & 91 & 0.66 \\
\hline 6 & 83.3 & $\mathrm{~b}$ & & & & & & 101 & 80 & 89.1 & 89 & 0.78 & 0.61 & 161 & 60 & 86.2 & 88 & 0.8 \\
\hline 6 & 83.3 & $\mathrm{~b}$ & & & & & & 102 & 60 & 92.2 & 95 & 0.5 & 0.42 & 162 & 75 & 84.2 & 86 & 0.94 \\
\hline 9 & 88.9 & 45 & 80 & 68.2 & 71 & 20.37 & 3.74 & 103 & 82 & 91.3 & 95 & 1.07 & 0.76 & 163 & 79 & 75.1 & 77 & 2.66 \\
\hline 9 & 88.9 & 46 & 85 & 82.6 & 90 & 3.61 & 1.68 & 104 & 80 & 88.5 & 90 & 1.66 & 1.04 & 164 & 95 & 92.4 & 94 & 0.66 \\
\hline 9 & 88.9 & 47 & 80 & 82.1 & 88.5 & 3.84 & 1.74 & 105 & 79 & 90.7 & 91 & 1.18 & 0.82 & 165 & 80 & 89.5 & 90 & 0.94 \\
\hline 9 & 88.9 & 48 & 70 & 85.9 & 88.5 & 2.37 & 1.32 & 106 & 75 & 93.5 & 95 & 0.71 & 0.56 & 166 & 58 & 85.4 & 94 & 1.36 \\
\hline 9 & 88.9 & 49 & 60 & 77.9 & 80 & 6.37 & 2.27 & 107 & 80 & 89.6 & 90 & 1.41 & 0.93 & 167 & 78 & 82.8 & 88 & 1.67 \\
\hline 9 & 88.9 & 50 & 70 & 82.2 & 89 & 3.8 & 1.73 & 108 & 81 & 85.6 & 88 & 2.47 & 1.35 & 168 & 89 & 87.4 & 88 & 1.15 \\
\hline 9 & 88.9 & 51 & 85 & 83.6 & 88 & 3.19 & 1.57 & 109 & 80 & 87.3 & 89 & 1.96 & 1.17 & 169 & 90 & 86.2 & 90 & 1.28 \\
\hline 9 & 88.9 & 52 & 55 & 84 & 85 & 3.03 & 1.52 & 110 & 83 & 89.7 & 90 & 1.39 & 0.92 & 170 & 87 & 92.4 & 95 & 0.66 \\
\hline 9 & 88.9 & 53 & 75 & 86.2 & 89 & 2.28 & 1.28 & 111 & 83 & 90.4 & 92 & 1.24 & 0.85 & 171 & 15 & 85.3 & 91 & 1.38 \\
\hline 9 & 88.9 & 54 & 85 & 79.5 & 81 & 5.27 & 2.06 & 112 & 80 & 89.6 & 90 & 1.41 & 0.93 & 172 & 56 & 82.5 & 87 & 1.7 \\
\hline 9 & 88.9 & b & & & & & & 113 & 85 & 92.3 & 95 & 0.9 & 0.67 & 173 & 70 & 86.9 & 88 & 1.21 \\
\hline 9 & 88.9 & $\mathrm{~b}$ & & & & & & 114 & 80 & 88.1 & 90 & 1.76 & 1.08 & 174 & 85 & 89.3 & 91 & 0.96 \\
\hline
\end{tabular}

a $N-1$ is the number of computerized competitors in the experiment.

b Due to network problems only 10 computers could be used in three sessions. Thus, only 54 subjects participated in $T 0$. 


\section{References}

Abbink, K., Sadrieh, A., 1995. Ratimage, research assistance toolbox for computer-aided human behavior experiments. Discussion paper B-325. University of Bonn.

Albers, W., 2001. Prominence theory as a tool to model boundedly rational decisions. In: Selten, R., Gigerenzer, G. (Eds.), Bounded Rationality: The Adaptive Toolbox. MIT Press.

Camerer, C.F., 2003. Behavioral Game Theory: Experiments in Strategic Interaction. University Press, Princeton.

Cason, T.N., Friedman, D., 1997. Price formation in single call markets. Econometrica 65, 311-345.

Cason, T.N., Friedman, D., 1999. Learning in laboratory market with random supply and demand. Exper. Econ. 2, 77-98.

Chen, K.-Y., Plott, C.R., 1998. Nonlinear behavior in sealed-bid first-price auctions. Games Econ. Behav. $25,34-78$.

Coppinger, V., Smith, V.L., Titus, J., 1980. Incentives and behavior in English, Dutch, and sealed-bid auctions. Econ. Inquiry $18,1-22$.

Cox, J.C., Roberson, B., Smith, V.L., 1982a. Theory and behavior of single object auctions. In: Smith, V.L. (Ed.), Research in Experimental Economics, vol. 2. JAI Press, Greenwich.

Cox, J.C., Smith, V.L., Walker, J.M., 1982b. Auction market theory of heterogeneous bidders. Econ. Letters 9, 319-325.

Cox, J.C., Smith, V.L., Walker, J.M., 1983a. Tests of a heterogeneous bidders theory of first-price auctions. Econ. Letters 12, 207-212.

Cox, J.C., Smith, V.L., Walker, J.M., 1983b. A test that discriminates between two models of the Dutch-first auction non-isomorphism. J. Econ. Behav. Organ. 4, 205-219.

Cox, J.C., Smith, V.L., Walker, J.M., 1984. Theory and behavior of multiple unit discriminative auctions. J. Finance 39, 983-1010.

Cox, J.C., Smith, V.L., Walker, J.M., 1985a. Experimental development of sealed-bid auction theory: Calibrating controls for risk aversion. Amer. Econ. Rev. (Papers and Proceedings) 75, 160-166.

Cox, J.C., Smith, V.L., Walker, J.M., 1985b. Expected revenue in discriminative and uniform-price sealed-bid auctions. In: Smith, V.L. (Ed.), In: Research in Experimental Economics, vol. 3. JAI Press, Greenwich.

Cox, J.C., Smith, V.L., Walker, J.M., 1987. Bidding behavior in first-price sealed-bid auctions: Use of computerized Nash competitors. Econ. Letters 23, 239-244.

Cox, J.C., Smith, V.L., Walker, J.M., 1988. Theory and individual behavior of first-price auctions. J. Risk Uncertainty 1 , 61-99.

Cox, J.C., Smith, V.L., Walker, J.M., 1992. Theory and misbehavior of first-price auctions: Comment. Amer. Econ. Rev. 82, 1392-1412.

Dorsey, R.E., Razzolini, L., 2003. Explaining overbidding in first-price auctions using controlled lotteries. Exper. Econ. 6, $123-140$.

Dufwenberg, M., Gneezy, U., 2002. Information disclosure in auctions: An experiment. J. Econ. Behav. Organ. 48, 431-444.

Dyer, D., Kagel, J.H., Levin, D., 1989. Resolving uncertainty about the number of bidders in independent private-value auctions: An experimental analysis. RAND J. Econ. 20, 268-279.

Friedman, D., 1992. Theory and misbehavior of first-price auctions: Comment. Amer. Econ. Rev. 82, 1374-1378.

Goeree, J.K., Holt, C.A., Palfrey, T.R., 2002. Quantal response equilibrium and overbidding in private-value auctions. J. Econ. Theory 104, 247-272.

Harrison, G.W., 1989. Theory and misbehavior of first-price auctions. Amer. Econ. Rev. 79, 749-762.

Harrison, G.W., 1990. Risk attitudes in first-price auction experiments: A Bayesian analysis. Rev. Econ. Statist. 72 , 541-546.

Harrison, G.W., 1992. Theory and misbehavior of first-price auctions: Reply. Amer. Econ. Rev. 82, $1426-1443$.

Isaac, R.M., Walker, J.M., 1985. Information and conspiracy in sealed-bid auctions. J. Econ. Behav. Organ. 6, $139-159$.

Kagel, J.H., 1995. Auctions: A survey of experimental research. In: Kagel, J.H., Roth, A.E. (Eds.), Handbook of Experimental Economics. Princeton Univ. Press, NJ.

Kagel, J.H., Levin, D., 1993. Independent private-value auctions: Bidder behavior in first-, second-, and third-price auctions with varying numbers of bidders. Econ. J. 103-419, 868-879.

Kagel, J.H., Levin, D., 1999. Common value auctions with insider information. Econometrica 67, 1219-1238.

Kagel, J.H., Roth, A.E., 1992. Theory and misbehavior of first-price auctions: Comment. Amer. Econ. Rev. 82, 13791391.

Kagel, J.H., Harstad, R., Levin, D., 1987. Information impact and allocation rules in auctions with affiliated private values: A laboratory study. Econometrica 55, 1275-1304.

Merlo, A., Schotter, A., 1992. Theory and misbehavior of first-price auctions: Comment. Amer. Econ. Rev. 82, 14131425 . 
Neugebauer, T., 2004. Bidding strategies of sequential first-price auctions programmed by experienced bidders. Cuadernos Econ. 75 (3), 153-184.

Neugebauer, T., Perote, J., 2005. Bidding 'as if' risk neutral in experimental first-price auctions without information feedback. Mimeo. University Hannover.

Neugebauer, T., Pezanis-Christou, P., in press. Bidding at sequential auctions with(out) supply uncertainty: An experimental investigation. J. Econ. Behav. Organ.

Ockenfels, A., Selten, R., 2005. Impulse balance theory and feedback in first-price auctions. Games Econ. Behav. 51, $155-170$

Selten, R., 2004. Learning direction theory and impulse balance equilibrium. In: Friedman, D., Cassar, A. (Eds.), Economics Lab-An Intensive Course in Experimental Economics. Routledge, NY, pp. 133-140.

Selten, R., Buchta, J., 1994. Experimental sealed-bid first price auctions with directly observed bid functions. (Discussion paper B-270. University of Bonn.) In: Budescu, D., Erev, I., Zwick, R. (Eds.), Games and Human Behavior: Essays in the Honor of Amnon Rapoport. Lawrenz Associates, Mahwah, NJ.

Selten, R., Stoecker, R., 1986. End behavior in sequences of finite prisoners' dilemma supergames: A learning theory approach. J. Econ. Behav. Organ. 7, 47-70.

Selten, R., Abbink, K., Cox, R., 2005. Learning direction theory and the winner's curse. Exper. Econ. 8, 5-20.

Smith, V.L., Walker, J.M., 1993. Rewards, experience and decision costs in first-price auctions. Econ. Inquiry 31, 237245.

Van Boening, M.V., Rassenti, S.J., Smith, V.L., 1998. Numerical computation of equilibrium bid functions in a first-price auction with heterogeneous risk attitudes. Exper. Econ. 1, 147-159.

Vickrey, W., 1961. Counter-speculation, auctions, and competitive sealed tenders. J. Finance 16, 8-37. 